Portland State University

PDXScholar

Civil and Environmental Engineering Faculty

Publications and Presentations

Civil and Environmental Engineering

2016

\title{
Accuracy of Bicycle Counting with Pneumatic Tubes in Oregon
}

Krista Nordback

Portland State University, nordback@pdx.edu

Sirisha Murthy Kothuri

Portland State University

Taylor Phillips

Portland State University

Carson Gorecki

Portland State University

Miguel Figliozzi

Portland State University, figliozzi@pdx.edu

Follow this and additional works at: https://pdxscholar.library.pdx.edu/cengin_fac

Part of the Transportation Commons, Urban Studies Commons, and the Urban Studies and Planning Commons

Let us know how access to this document benefits you.

Citation Details

Nordback, K., Kothuri, S., Phillips, T., Gorecki, C., \& Figliozzi, M. (2016). Accuracy of Bicycle Counting with Pneumatic Tubes in Oregon. http://dx.doi.org/10.3141/2593-02.

This Post-Print is brought to you for free and open access. It has been accepted for inclusion in Civil and Environmental Engineering Faculty Publications and Presentations by an authorized administrator of PDXScholar. Please contact us if we can make this document more accessible: pdxscholar@pdx.edu. 


\section{ACCURACY OF BICYCLE COUNTING WITH PNEUMATIC TUBES IN OREGON}

\section{Paper 16-2118}

Corresponding author:

Krista Nordback

Transportation Research and Education Center (TREC)

Portland State University

PO Box 751 - TREC

Portland, Oregon 97207-0751

Tel: 503-725-2897 Email: nordback@pdx.edu

\section{Sirisha Kothuri}

Department of Civil and Environmental Engineering

Portland State University

PO Box 751 CEE

Portland, Oregon 97207-0751

Tel: 503-725-4208 Email: skothuri@pdx.edu

\section{Taylor Phillips}

Transportation Research and Education Center (TREC)

Portland State University

PO Box 751 - TREC

Portland, Oregon 97207-0751

Tel: 503-725-8545 Email: tphill2@pdx.edu

\section{Carson Gorecki}

Transportation Research and Education Center (TREC)

Portland State University

PO Box 751 - TREC

Portland, Oregon 97207-0751

Tel: 503-725-8545 Email: cgorecki@pdx.edu

\section{Miguel Figliozzi}

Professor, Department of Civil and Environmental Engineering

Portland State University

PO Box 751 CEE

Portland, Oregon 97207-0751

Tel: 503-725-2836 Email: figliozzi@pdx.edu

Word count: 5384 words text

Tables \& Figures: 8

Submission Date: November 14, 2015 


\begin{abstract}
Interest in counting bicycles and establishing non-motorized counting programs is increasing, but jurisdictions still struggle with how to integrate bicycle counting into standard practice. In this paper, the authors share findings and recommendations for how to minimize error for bicycle counting, based on tests conducted in conjunction with the Oregon Department of Transportation. This research studied three types of off-the-shelf pneumatic tube counters for counting bicycles, including equipment from five manufacturers: two bicycle-specific counters, three varieties of motor-vehicle classification counters, and one volume-only motor-vehicle counter. Tests were conducted both in a controlled environment and in on-road mixed traffic in order to better identify problems in accuracy. Equipment studied generally undercounted cyclists, especially those in groups. Results from the controlled test with standard bicycles showed that within 10 feet of the counter, the undercounting error ranged from 0 to $-12 \%$. In the mixed traffic test, all of the equipment tested tended to undercount with mean percent error ranging from $-10 \%$ to $-73 \%$. Each counter type has pros and cons but, in general, counting accuracy decreased with increases in bicycle and motor-vehicle traffic and longer tube lengths. Higher accuracy can be achieved by a careful selection of equipment type, classification scheme, and tube configuration. Bicycle speeds given by off-the-shelf pneumatic counting equipment were accurate.
\end{abstract}




\section{INTRODUCTION}

Over the last decade, there has been increased interest in counting bicycles and establishing nonmotorized counting programs, as exemplified by inclusion of an entire chapter of the 2013 edition of the Traffic Monitoring Guide devoted to bicycle and pedestrian counting methods and technologies (1). However, jurisdictions still struggle with how to integrate bicycle counting into standard practice.

Would it be possible for jurisdictions to use the same pneumatic tubes that are currently used for short-duration motor-vehicle counts to count bicycles? If so, how can this be accomplished? In this paper, the authors address these questions and share findings and recommendations for how to maximize accuracy while minimizing the number and types of counters needed for bicycle counting, based on tests conducted in conjunction with the Oregon Department of Transportation (ODOT).

While others have also addressed these questions $(2,3)$, this study examines more types of pneumatic tube equipment than have previously been included in one study and compares equipment performance in a controlled environment and in mixed traffic in order to better identify problems in accuracy. This research studied three types of off-the-shelf pneumatic tube counters, including equipment from five manufacturers: two bicycle-specific counters, three varieties of motor-vehicle classification counters, and one volume-only motor-vehicle counter. This study also examines speed estimates using pneumatic tubes and how bicycle and automobile traffic volume affect accuracy.

\section{BACKGROUND}

Bicycle and pedestrian counting techniques are continuously evolving. To summarize the state of the practice, TRB's bicycle and pedestrian data subcommittee developed a research circular in 2014 (4).

Another recent research report, NCHRP 797, provides a broader overview of the steps necessary to establish counting programs, reviews technologies for counting non-motorized travel and provides case studies of jurisdictions' experiences with collecting bicycle and pedestrian count data (5). A number of technologies have been utilized to count bicycles for short- and long-term purposes.

The most widely used automated technologies for counting bicycles are inductive loops, pneumatic tubes and infrared (in combination with inductive loops or pneumatic tubes to distinguish bicycles from pedestrians). Automated video imaging, piezoelectric strips, magnetometers, radio beam and thermal imaging are also used. For the purposes of shortduration bicycle counts, pneumatic tubes, infrared, and manual counts are commonly used. Automated counters are preferred, since manual counts (collected in the field or by reducing video in the office) require more staff time per hour of data collected. Previous research has found that at least one week of counts is desirable to minimize error in estimating annual bicycle traffic volumes (6-8). Of the two common portable automated count technologies (infrared and pneumatic tubes), only tubes are able to identify and count bicycles without counting pedestrians or equestrians. Therefore, this paper will focus on pneumatic tubes.

Pneumatic tubes are commonly used to gather short-duration motor-vehicle counts. Recently, there has been a push to adapt this technology to count bicycles in addition to motor vehicles. Pneumatic tube equipment consists of two main elements: pneumatic tubes laid across a roadway or path and a data recorder. As vehicles or bicycles pass over the tubes, pulses of air travel through the tubes to the data recorder, which detects them due to change in pressure. These tubes 
are portable, and a widely available technology. Three types of pneumatic tubes are available commercially:

a) Bicycle-specific Counters - These are dual tube configurations, specifically designed for bicycle counts. They differentiate between motor vehicles and bicycles, but provide bicycle counts only and can be used in a shared lane with mixed traffic.

b) Classification Counters - These are dual tube configurations for motor vehicle classification counts. Some equipment in this category can classify both motor vehicles and bicycles in mixed traffic, when adjustments are made and bicycle-specific classification schemes are used.

c) Volume Counters - These are single tube configurations for motor-vehicle traffic volume counts without any classification ability. These can be used to count bicycles in a dedicated bicycle lane or path, but they cannot distinguish between bicycles and vehicles in mixed traffic.

There is limited research regarding the performance of pneumatic tubes to count bicycles. Boulder County, Colorado evaluated the performance of one type of classification counter and bicycle-specific pneumatic tube counters at various sites (2). Their results revealed that bicycle-specific counters were more reliable and accurate than classification counters when counting bicycles; however they observed a drop in accuracy as the distance from the counter increased (2). A Norwegian study also tested classification counters and bicycle-specific tube counters and found high accuracy for bicycle-specific counters (over 95\%), but only 70 to $75 \%$ accuracy for the classification counter (9). A study from New Zealand also examined a bicyclespecific tube counter and a classification counter with similar results: nearly $100 \%$ of bicycles were counted with the bicycle-specific tubes and $85 \%$ to $90 \%$ with the classification counter (10).

More recently, Brosnan et al. also conducted tests of two classification counters and bicycle-specific tube counters on two different facilities in Minnesota (3). Their results revealed lower error on the lower volume facility. In addition, undercounting was a significant issue, primarily due to occlusion, in which two vehicles simultaneously cross the tubes such that the air pulses from both cannot be differentiated. They found that bicycle-specific counters had higher accuracy than general traffic counters and developed adjustment factors to adjust for the error.

NCHRP 797 also tested bicycle-specific tube counters and found that they typically undercount, with some models outperforming others. Mean percent errors of $11 \%$ and $53 \%$ undercounts were obtained for the two products (11).

The purpose of this study is to provide guidance for agencies, which seek to integrate bicycle counting with their existing short-duration motor-vehicle counting programs by examining the performance of currently available off-the-shelf pneumatic tube counters for counting bicycles. Using the same tubes to count bicycles and motor vehicles can help in minimizing the number of counters that an agency has to maintain in their inventory.

\section{EQUIPMENT}

The research team tested three types of off-the-shelf pneumatic tube counters: volume, classification, and bicycle-specific counters (Table 1). For simplicity, each piece of equipment tested is designated by a letter number combination for reference in this paper. The diameters of the tubes themselves varied, but were generally in two categories: road tubes and mini tubes. 
Exact dimensions are given in Table 1. Tube lengths also varied as shown in Figures 1 and 2.

Two bicycle-specific counters were studied, B1 and B2. Both are available commercially and provided by the same manufacturer. Like the classification counters, these use two tubes placed on the roadway; however, they provide only binned, not time-stamped, counts (15-minute bins) and do not provide axle hit data. B1 provides bicycle counts only, whereas B2 provides bicycle and motor vehicles separately, but provides no classification for motor vehicles.

Three classification counters were tested, referred to as $\mathrm{C} 1$ through $\mathrm{C} 3$ as listed in Table 1. The vendors for each claimed that the equipment was able to classify and count bicycles and motor vehicles in mixed traffic. Installation consists of two tubes laid across the roadway. These classifiers record every axle that passes over the tube and use a classification scheme to classify the axle hits into vehicle types, including bicycles. $\mathrm{C} 1$ and $\mathrm{C} 3$ provide timestamps and speed for each vehicle classified, while $\mathrm{C} 2$ provides counts in 1-minute bins. $\mathrm{C} 2$ and $\mathrm{C} 3$ allow the user to select different classification schemes.

TABLE 1 Equipment Tested

\begin{tabular}{|c|c|c|c|c|c|}
\hline Type & Designation & Make & Model & Tubes & Comments \\
\hline \multirow[t]{2}{*}{ Bicycle-specific } & B1 & Eco-Counter & $\begin{array}{l}\text { Bicycle only } \\
\text { TUBES }\end{array}$ & $\begin{array}{l}0.3 \text { in. ID } \\
0.6 \text { in. OD }\end{array}$ & $\begin{array}{l}\text { Vendor specific } \\
\text { tubes }\end{array}$ \\
\hline & B2 & Eco-Counter & $\begin{array}{l}\text { Bicycle/motor- } \\
\text { vehicle } \\
\text { TUBES }\end{array}$ & $\begin{array}{l}0.3 \text { in. ID } \\
0.6 \text { in. OD }\end{array}$ & $\begin{array}{l}\text { Vendor specific } \\
\text { tubes }\end{array}$ \\
\hline \multirow{3}{*}{ Classification } & $\mathrm{C} 1$ & $\begin{array}{l}\text { JAMAR } \\
\text { Technologies, Inc. }\end{array}$ & $\begin{array}{l}\text { TRAX Cycles } \\
\text { Plus }\end{array}$ & $\begin{array}{l}0.2 \text { in. ID } \\
0.4 \text { in. OD }\end{array}$ & $\begin{array}{l}\text { Also estimates } \\
\text { speeds }\end{array}$ \\
\hline & $\mathrm{C} 2$ & $\begin{array}{l}\text { Time Mark } \\
\text { Corporation }\end{array}$ & Gamma & $\begin{array}{l}0.3 \text { in. ID } \\
0.7 \text { in. OD }\end{array}$ & $\begin{array}{l}\text { Also estimates } \\
\text { speeds }\end{array}$ \\
\hline & $\mathrm{C} 3$ & MetroCount & MC5600 & $\begin{array}{l}0.2 \text { in. ID } \\
0.4 \text { in. OD }\end{array}$ & Natural rubber tubes \\
\hline Volume & V1 & $\begin{array}{l}\text { Diamond Traffic } \\
\text { Products }\end{array}$ & TT-6 & $\begin{array}{l}0.3 \text { in. ID } \\
0.7 \text { in. OD }\end{array}$ & Single tube \\
\hline
\end{tabular}

One volume-only counter was tested, referred to in this paper as V1. It does not distinguish between bicycles and motor vehicles. Installation consists of a single road tube laid across the roadway. Data for each counter was downloaded and processed using vendor supplied software.

\section{METHODS}

The research team conducted two tests: a controlled environment test with only bicycle traffic and a mixed traffic test on a state highway. Each will be discussed separately below followed by a discussion of performance metrics.

\section{Controlled Environment Test}

The purpose of the controlled environment test was to a) understand the limitations of the equipment in the situation most advantageous for accurate counts, b) study the ability of each counter to correctly count bicycles in especially challenging cases and c) potentially eliminate some counting technologies from the mixed traffic test based on their performance. This test was also an opportunity for the ODOT crew and Portland State University (PSU) research team to gain further understanding of the equipment setup.

The test was conducted at ODOT's Traffic Systems Services Unit parking lot in Salem, Oregon on Monday, February $23^{\text {rd }}$, 2015, a sunny day with high temperature around 60 degrees Fahrenheit. Figure 1 shows the pneumatic tube setup, including their length and distance between 
tubes. The excess tube length shown in Figure 1 is the length of tube between the anchor point (nail) and the counting device (box). For example, for V1 tubes the distance between the anchor point and the counting device is 3.5 feet. B2 was not tested in this first test, as it was not available at the time of testing. Traffic video cameras mounted on poles recorded the test in order to count bicycles for ground truth.

Prior to the test, the research team met at the test site with vendors of various equipment to ensure that it was set up and calibrated properly. The research team also recruited volunteers from ODOT staff and other transportation professionals to ride over the pneumatic tube. Participants were asked to ride over the tubes first in one direction for half an hour and then in the opposite direction for half an hour. This was repeated twice for a total of two hours of testing. Each half hour was broken into five-minute increments, one five-minute increment for Zones 1 through 6 (Figure 1). Zone 7 was tested separately for only one ten-minute period consisting of 5 minutes in each direction. Thus, the ability of the technologies to detect and count bicycles in both directions and at various distances from the counting device was tested.

Prior to the commencement of tests, the clocks for the counting equipment were synchronized, which enabled comparison with the recorded video. In addition to obtaining manual counts from video, the research team also counted bicyclists manually by time and zone during the test. The bicycles used during this phase of testing consisted of standard wheelbase, steel and aluminum frame, mountain, hybrid and road bicycles ridden by eight adult volunteers.

Following the standard bikes test, special cases were investigated: tandems, bicycles with trailers, carbon fiber bikes, cargo bicycles, and bicyclists riding one behind the other and side by side. The purpose of this test was to understand how well the technologies are able to count special cases of bicycles that are encountered less frequently on the roadway. For the special cases tests, bicyclists were asked to ride in Zone 1 for the tubes at all times. 


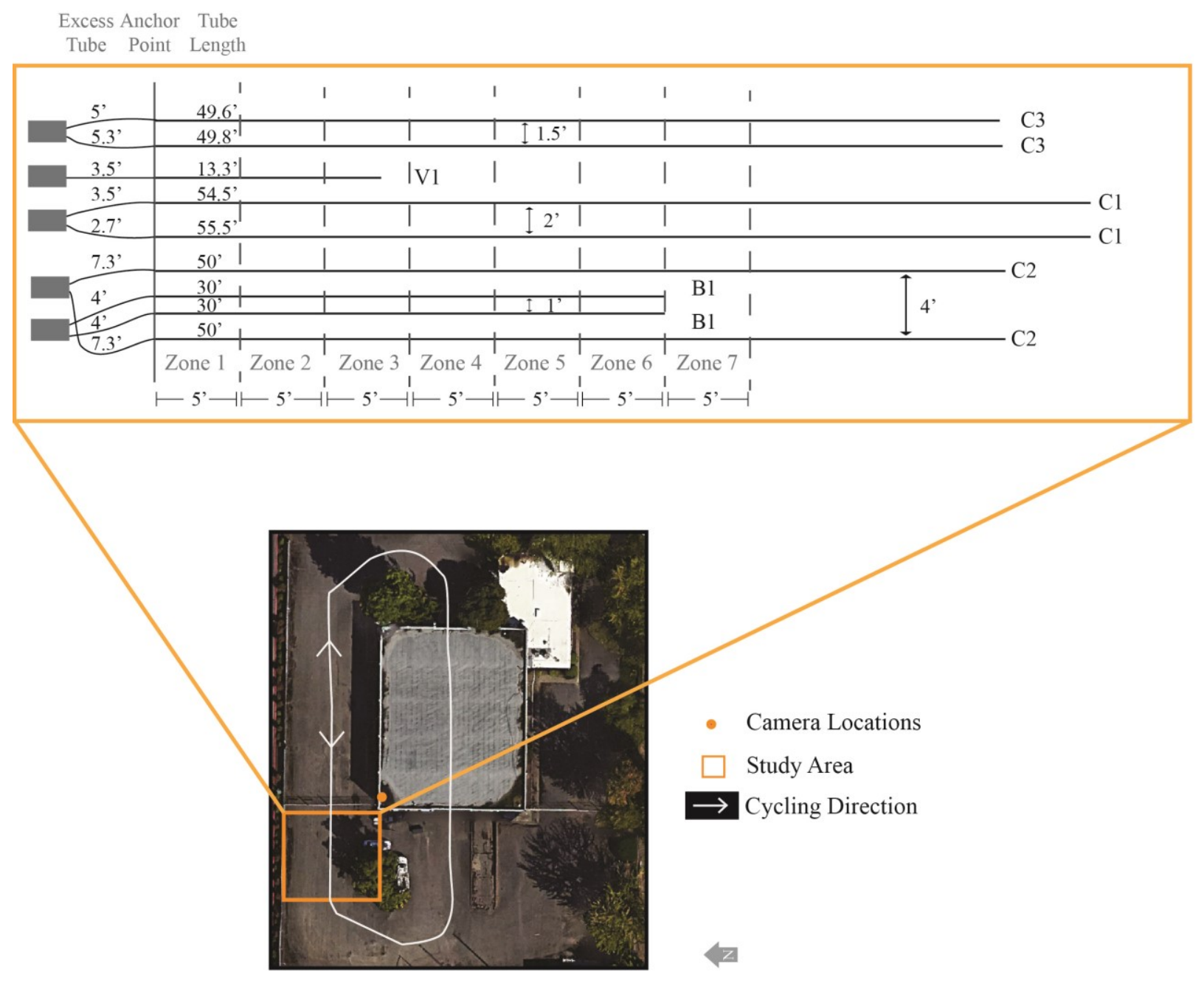

FIGURE 1 Layout of Pneumatic Tube Counters for Controlled Environment Test.

\section{Mixed Traffic Test}

In order to evaluate the performance of the counting equipment in a real-world scenario, the pneumatic tube counters were tested on a state highway with relatively high bicycle volumes. To minimize tube displacement due to turning, accelerating or decelerating vehicles, the team sought a relatively flat and straight section of roadway in a rural setting. Other criteria for selecting a site included proximity to Portland to minimize travel time, moderate to high bicycle traffic volume, and a cross-section representative of ODOT highways. The highway section selected was a twolane section with four to five-foot shoulders on the Historic Columbia River Highway, a road used by tourist traffic and cyclists to access a scenic portion of the Columbia River Gorge east of Corbett, Oregon. The slight grade provided the opportunity to study one direction with higher bicycle speeds (15-30 $\mathrm{mph}$ ) and the other with slower bicycles $(5-15 \mathrm{mph})$. The roadway width of 32.5-feet allowed researchers to test how well one counter could count cyclists on both shoulders.

It was important to study actual traffic, not traffic generated by volunteer riders, since actual bicycle traffic may behave differently than recruited riders. To maximize the number of 
bicycles observed during the test, a three-day holiday weekend with high bicycle volumes was selected: Memorial Day weekend, Friday, May 22, 2015 through Monday, May 25, 2015. The weekend contained hours of both high and low bicycle and motor-vehicle traffic, partly cloudy skies, high temperatures between 60 and 70 degrees Fahrenheit and some rain. A total of 576 cyclists, 300 eastbound (EB) and 276 westbound (WB) were observed during daylight hours (8:00 AM to 8:00 PM) from the manually counted video during the four days (46 hours) studied. Two hours on Sunday were lost due to camera downtime while switching data storage cards. The video was collected using two ODOT traffic observation cameras: one mounted on a luminaire pole and the other on a signpost. Two cameras were installed for redundancy, but only the closer camera on the signpost functioned properly.

Since preliminary results for all the equipment tested were sufficiently accurate (less than $10 \%$ error for bicycles 10 to 15 feet of the counter), the same equipment that was used in the controlled environment test was tested in the mixed traffic test, with the addition of B2, which was not available previously. As shown on Figure 2, tubes were laid out on both the north and south side of the roadway. This tested the hypothesis that counts closer to the detector would be more accurate based on previous studies and findings from the controlled environment test. Thus, an effort was made to repeat the tube set up on each side of the roadway. ODOT transportation monitoring staff set up all of the tubes and the V1 and $\mathrm{C} 2$ data loggers. In order to test both standard setup for motor-vehicle classification counts (16-foot spacing) and a spacing recommended by the manufacturer for bicyclists and motor-vehicles classification (10-foot spacing), ODOT set up two sets of $\mathrm{C} 2$ equipment on each side of the road with different tube spacings. The PSU research team set up the $\mathrm{C} 1, \mathrm{C} 3, \mathrm{~B} 1$ and $\mathrm{B} 2$ data loggers.

The volume count tubes, V1, were only set up on the shoulder, since they cannot differentiate between motorists and bicyclists. They were included in order to study whether bicyclists would avoid the tubes or motorists drive over them. To test whether cyclists avoided the tubes, these were set up in front of the other tubes so that cyclists could avoid them, though they could not avoid the other tubes.

In order to ensure that our "ground truth" video counts were accurate, the three researchers who counted bicycles for the study all counted the same one hour of video from the Sunday test during the hour from 10:00 a.m. to 11:00 a.m. While counts between researchers were slightly different when classifying motor vehicles, all three counted 32 bicycles during the hour (100\% inter-rater reliability). 


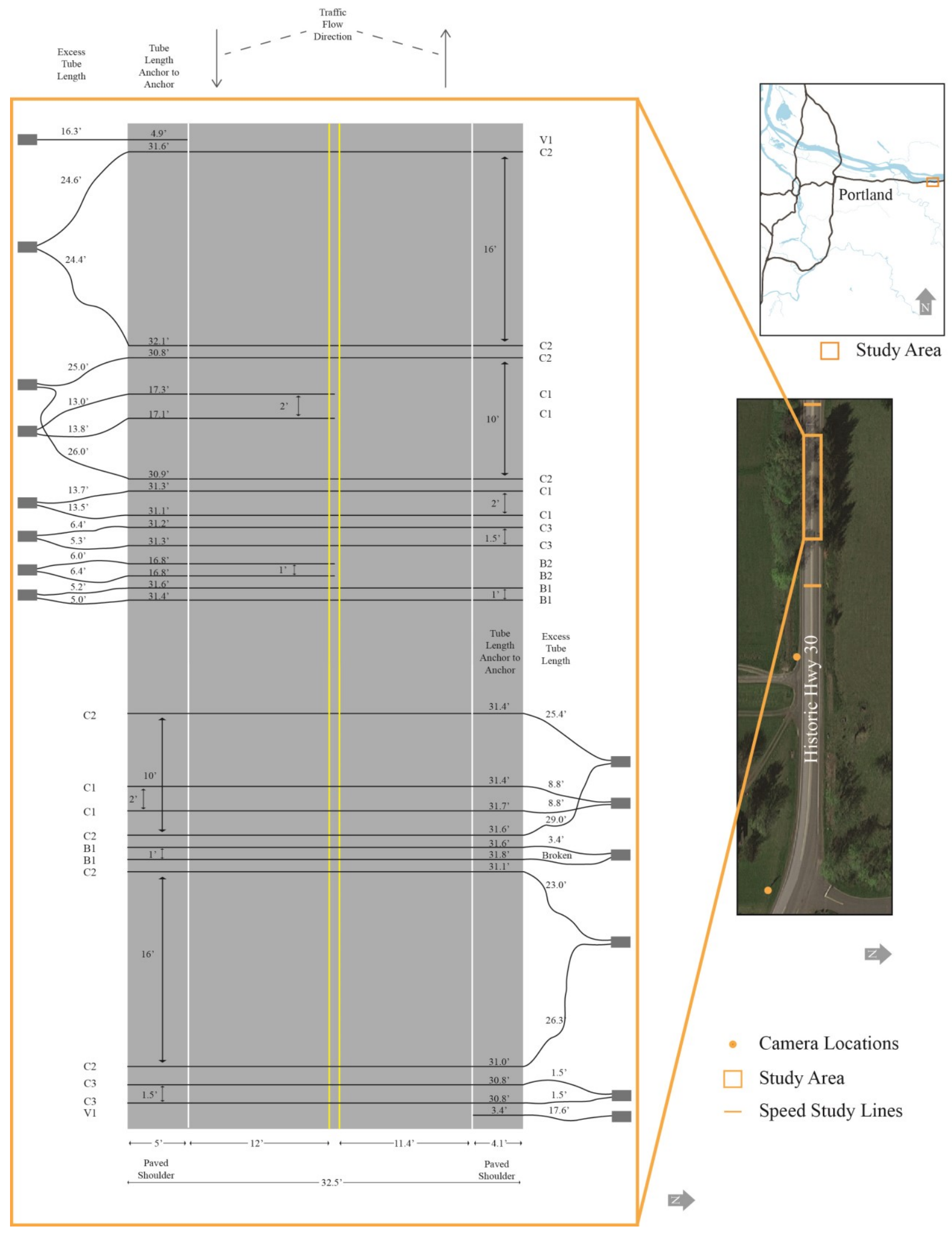

FIGURE 2 Layout of Pneumatic Tube Counters for Mixed Traffic Test. 


\section{Performance Metrics}

The following metrics were used to compare accuracy: overall error, mean percent error (MPE) and mean absolute percent error (MAPE). These are equivalent to the average percent deviation and average absolute percent deviation metrics used in NCHRP 797. To compute these metrics, the counts from the automated equipment were compared to ground truth counts. The ground truth for the controlled environment and special cases tests was the count collected by manual counters in the field, which was later verified by video counts. The ground truth for the mixed traffic test was manually counted video.

Overall error is computed for the entire study period: two hours for the controlled environment standard bicycle test, 20 minutes for each category in the special cases test, and 46 hours for the mixed traffic test. Overall error was calculated as the difference between the ground truth and counting equipment count divided by the total ground truth count for the study period as explained in Equation 1.

where

$$
\text { Overall Error }=\frac{c-m}{m}
$$

$m=$ ground truth count for study period

$c=$ tube count for study period

While overall error gives a big picture view, it does not reveal the likelihood of a false negative (cyclist is present but not counted) or a false positive (a cyclist is counted, when not present). If each counter provided time stamps for every event, these false positives and false negatives could be counted. Unfortunately, since some of the equipment binned their data in 1-minute (C2) and 15-minute (B1 and B2) bins, it was not possible to compute the true number of false positives and negatives across all equipment types. However, by binning the data, it is possible to compute the error per bin or count interval and observe over and undercounts per count interval. The count intervals varied by equipment for the controlled environment and special cases test, ranging from five minutes to 15 minutes. The count interval for the mixed traffic test was one hour for all equipment types. In intervals with no bicycles and no counts, interval error was assigned a zero value.

$e_{i}=$ interval error $=$ error for the count interval $i$

$$
e_{i}=\frac{c_{i}-m_{i}}{m_{i}}
$$

$m_{i}=$ ground truth count for count interval $i$

$c_{i}=$ tube count for count interval $i$

MPE was calculated by averaging the errors for each count interval for the entire study period.

where

$$
M P E=\frac{1}{h} \sum_{i=1}^{h} e_{i}
$$

$h=$ the total number of count intervals counted in the study period

Similarly, the MAPE was calculated by averaging the absolute value of the errors for each count interval for the entire study period.

$$
M A P E=\frac{1}{h} \sum_{i=1}^{h}\left|e_{i}\right|
$$




\section{FINDINGS}

\section{Controlled Environment Test}

Table 2 shows the errors across zones for all tube counters that were tested, with undercounting observed for all equipment. In Zones 1-3, most of the tube counters were fairly accurate. As the distance from the counter increased, all three classification counters showed higher errors. Of all counters tested, for standard bicycles, B1 was the most accurate with MPE of $-0.6 \%$, indicating a slight undercount. The number of cyclists for each zone $(n)$ was the same for all the equipment types, but varied by zone and averaged 85 cyclists per zone.

Cyclist speeds for this test were relatively slow, averaging eight miles per hour based on speeds reported by $\mathrm{C} 1$. This was due to sharp turns adjacent to the tube layout. Speeds were especially slow for Zones 4 through 7, which averaged only seven miles per hour.

TABLE 2 Error for Controlled Environment Test by Distance from Counter (Zone) for Standard Bicycles Only

\begin{tabular}{|c|c|c|c|c|c|c|c|c|c|}
\hline \multirow{2}{*}{$\begin{array}{c}\text { Type } \\
\text { Zone } \\
\end{array}$} & \multicolumn{7}{|c|}{ Percent Overall Error by Zone (\%) } & \multirow{2}{*}{$\begin{array}{l}\text { MPE } \\
(\%)\end{array}$} & \multirow{2}{*}{$\begin{array}{l}\text { MAPE } \\
(\%)\end{array}$} \\
\hline & 1 & 2 & 3 & 4 & 5 & 6 & 7 & & \\
\hline$n$ & 69 & 85 & 92 & 95 & 93 & 90 & 73 & & \\
\hline B1* & & 0.0 & & & -1.06 & & N/A & -0.6 & 1.7 \\
\hline C1 & 1.5 & 0.0 & 0.0 & -10.5 & -38.0 & -49.5 & -26.0 & -15.7 & 16.7 \\
\hline C2 & -7.3 & 0.0 & -5.3 & -6.3 & -25.0 & -53.9 & -82.2 & -16.2 & 16.6 \\
\hline $\mathbf{C 3}$ & -7.3 & -1.2 & -18.1 & -26.3 & -63.0 & -64.8 & -98.6 & -30.8 & 30.8 \\
\hline V1 & -11.6 & 6.0 & 3.2 & N/A & N/A & N/A & $\mathrm{N} / \mathrm{A}$ & -7.6 & 9.9 \\
\hline
\end{tabular}

* B1 counters provided data in 15 minute bins, so error is reported for groups: 1 to 3 and 4 to 6 .

Note: N/A indicates that the tubes were not long enough to reach these zones.

The results indicate that all of the equipment studied are viable technologies for counting bicycles within 0-10 ft. from the tube counter, approximately up to the width of one general traffic lane. Also, one particular counter is a viable technology to count in the range of 0-30 $\mathrm{ft}$. approximately up to two general traffic lanes. These results agree with findings from a prior research study, where researchers also reported drop in accuracy beyond $27 \mathrm{ft}$. for both bicyclespecific and general-purpose tube counters (2).

Table 3 shows the accuracy of the pneumatic tube counters during the special cases test. In the tandems and bikes with trailer category, both V1 and C2 counters showed the lowest error, with V1 overcounting by $4 \%$ and $\mathrm{C} 2$ undercounting by $4 \%$. In the carbon fiber, cargo bicycle category, B1 was most accurate with undercounting errors of $4 \%$. Both $\mathrm{C} 1$ and B1 were fairly accurate when counting bicycles riding one behind the other. All the tube counters showed high errors when counting bicycles riding side by side, indicating the limitation of pneumatic tube counting technology. 
TABLE 3 Error of Pneumatic Tube Counters with Special Cases

\begin{tabular}{l|r|r|r|r|r|r|r|r}
\hline Tube Counter & \multicolumn{2}{|c|}{$\begin{array}{c}\text { Tandem, Bike } \\
\text { with Trailer }\end{array}$} & \multicolumn{2}{c|}{$\begin{array}{c}\text { Carbon Fiber, } \\
\text { Cargo Bicycle }\end{array}$} & \multicolumn{2}{c|}{$\begin{array}{c}\text { Standard } \\
\text { Bicycles: One } \\
\text { Behind the Other }\end{array}$} & \multicolumn{2}{c}{$\begin{array}{c}\text { Standard } \\
\text { Bicycles: Side by } \\
\text { Side }\end{array}$} \\
\hline & $n$ & $\begin{array}{c}\text { Overall } \\
\text { Error (\%) }\end{array}$ & $n$ & $\begin{array}{c}\text { Overall } \\
\text { Error } \\
(\%)\end{array}$ & $n$ & $\begin{array}{c}\text { Overall } \\
\text { Error } \\
(\%)\end{array}$ & $n$ & $\begin{array}{c}\text { Overall } \\
\text { Error } \\
(\%)\end{array}$ \\
\hline B1 & 24 & -75 & 24 & -4 & 68 & -74 & 70 & -59 \\
\hline C1 & 46 & -50 & 54 & -50 & 116 & -2 & 118 & -46 \\
\hline C2 & 46 & -4 & 54 & -6 & 116 & -65 & 118 & -38 \\
\hline C3 & 46 & -96 & 54 & -56 & 116 & -95 & 118 & -57 \\
\hline V1 & 46 & 4 & 54 & -9 & 116 & -4 & 118 & -36 \\
\hline
\end{tabular}

Mixed Traffic Test

Error attributed to each counter varied substantially during the mixed traffic test as shown in Table 4. Undercounting was encountered with all tested counters, and error for all counting equipment was high ( $\geq 10 \%$ undercount MPE). The bicycle-specific counters had relatively low error $(20 \%$ to $23 \%$ undercount MPE). The classification counters varied widely with the error of least accurate equipment (C2 with $44 \%$ to $73 \%$ undercount $\mathrm{MPE}$ ) twice as high as the most accurate counters, $\mathrm{C} 1$ and $\mathrm{C} 3$ with $\mathrm{BOCO}$ classification scheme (10\% to $28 \%$ undercount MPE). The volume-only counter performed unexpectedly well with only $20 \%$ undercount MPE.

TABLE 4 Summary of Error for Mixed Traffic Tube Test

\begin{tabular}{|c|c|c|c|c|c|c|}
\hline Counter Name & $n$ & $\begin{array}{l}\text { Bicycles } \\
\text { Counted }\end{array}$ & $\begin{array}{l}\text { Overall } \\
\text { Error } \\
(\%)\end{array}$ & $\begin{array}{l}\text { MPE } \\
(\%)\end{array}$ & $\begin{array}{l}\text { MAPE } \\
(\%)\end{array}$ & $\begin{array}{l}\text { Total } \\
\text { Hourly } \\
\text { Over- } \\
\text { counts }\end{array}$ \\
\hline B1, north side, (total) & 576 & 361 & -37 & -23 & 26 & 2 \\
\hline B1, south side, (total) & 576 & 378 & -34 & -20 & 23 & 3 \\
\hline B2, south side (half road) & 300 & 183 & -39 & -20 & 26 & 2 \\
\hline C1, north side, (total) & 576 & 409 & -29 & -18 & 22 & 9 \\
\hline C1, south side, (total) & 576 & 400 & -31 & -13 & 31 & 15 \\
\hline C1, south side (half road) & 300 & 185 & -38 & -23 & 24 & 1 \\
\hline C2, north side, $10 \mathrm{ft}$, (total) & 576 & 170 & -70 & -50 & 55 & 3 \\
\hline C2, north side, $16 \mathrm{ft}$, (total) & 576 & 200 & -65 & -44 & 50 & 12 \\
\hline C2, south side, $10 \mathrm{ft}$, (total) & 576 & 142 & -75 & -60 & 60 & 1 \\
\hline C2, south side, $16 \mathrm{ft}$, (total) & 576 & 79 & -86 & -73 & 73 & 3 \\
\hline C3, north side, (total) ARXCycle & 576 & 236 & -59 & -43 & 43 & 0 \\
\hline C3, south side, (total) ARXCycle & 576 & 288 & -50 & -32 & 32 & 0 \\
\hline C3, north side, (total) BOCO & 576 & 380 & -34 & -28 & 29 & 1 \\
\hline C3, south side, (total) BOCO & 576 & 495 & -14 & -10 & 10 & 1 \\
\hline V1, north \& south sides, (total) & 576 & 425 & -26 & -20 & 27 & 20 \\
\hline
\end{tabular}


For $\mathrm{C} 1$, the manufacturer now provides bicycle-specific software, which can improve accuracy but was not available at the time of this test. For C3, Boulder County's improved classification scheme, BOCO (2) (not supplied with the manufacturer's software) greatly improves the accuracy of the C3 compared the manufacturer supplied scheme, ARXCycle.

Another metric of interest is the number of overcounts in a given hour bin. These overcounts for each technology are shown in the last column of Table 4. These "phantom cyclists" are especially obvious for hours in which no cyclists were observed in the video. Such overcounts are especially concerning if they are caused by misclassified motor vehicles, as this can cause the counters to report biased data with incorrect traffic patterns for bicycles. Such errors can be especially problematic for roads with low bicycle counts, a condition prevalent on state highways in the U.S. While B1 and C3 show relatively few overcounts, C1, C2, and V1 show more.

The research team also compared bicycle speeds recorded by various counters with measured speeds obtained by observing when each bicyclist passed a set of points during the mixed traffic test. The two points are shown in Figure 2. This comparison of average speeds for the study period shows that on average for each hour, the speed estimates for $\mathrm{C} 1$ and $\mathrm{C} 3$ agreed both with each other and with the manually computed speed. The bicycle speed for both directions combined averaged 17 to 19 miles per hour (mph) with an average of 12 to $13 \mathrm{mph}$ in the eastbound (uphill) direction and an average of 20 to $22 \mathrm{mph}$ in the westbound (downhill) direction.

As found in the controlled environment study, error was found to be significantly higher for bicyclists farther from the equipment. The error for cyclists on the opposite side of the road from the equipment was on average about one and a half times higher than the error for cyclists riding on the side nearest the equipment.

The excess tube length between the anchor and the data logger (Figure 2) increased the effective distance between the bicyclists and the equipment. The C2 tubes had the longest excess tube length ( 25 feet or more) and the highest error. While it may have been beneficial to test the counters with shorter and similar tube lengths, the tubes for C2 and V1 were on loan from ODOT, which uses them as part of their vehicle count program and therefore the length could not be altered.

A related question is whether shorter tubes that only covered one vehicle lane and the shoulder (half road) would yield more accurate results than longer tubes that covered the entire road. However, the error for the two half road cases (B2 and $\mathrm{C} 1$ half road) does not show substantially lower error than comparable equipment (B1 and $\mathrm{C} 1)$.

Error also varied by direction as shown in Figure 3, which shows generally higher error for eastbound (EB) than for westbound (WB) equipment. Perhaps this is due to higher error for lower speed bicycles, since bicycle speeds were higher in the westbound (downhill) direction. However, analysis of error with speed did not show a clear relationship between bicyclist speed and accuracy.

The spacing between tubes may also play a role in accuracy. The classification counters with the highest error (C2) also had the widest separation between tubes, but there does not appear to be a big difference between the 10-foot and 16-foot spacings for $\mathrm{C} 2$.

Does tube diameter impact error? This study did not identify a clear link between error and tube diameter. The large diameter tubes used with the $\mathrm{C} 2$ equipment did yield high errors, but the same tubes were used with the V1 equipment and did not result in high error. 


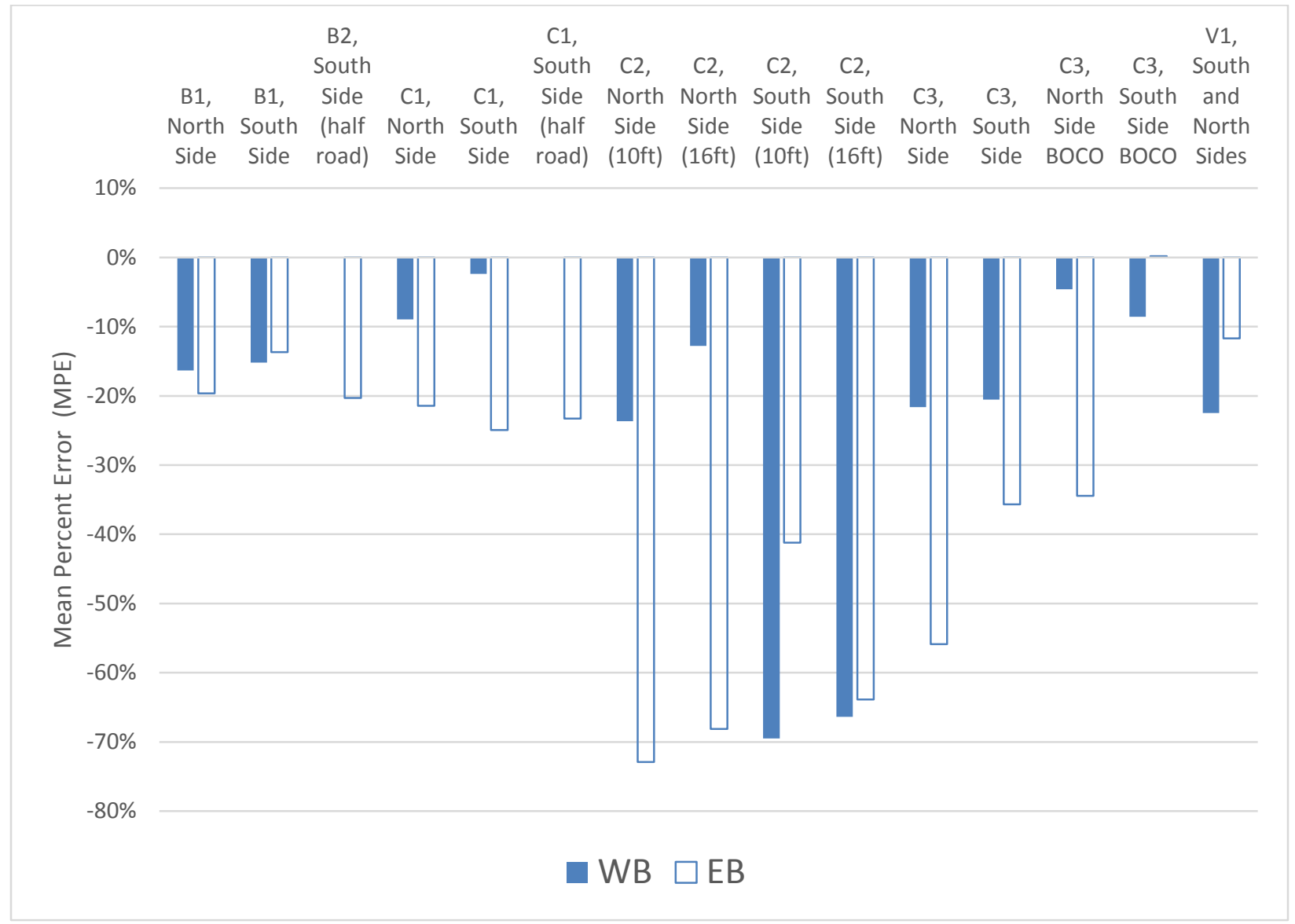

FIGURE 3 Error for Pneumatic Tube Counters in Mixed Traffic Test.

What is causing the error? Figure 4 examines error per count interval with bicycle and motor-vehicle traffic volumes. Based on this figure, error appears to increase with increasing bicycle traffic volumes and to a lesser extent with increasing motor-vehicle volumes. These results are intuitive since passing vehicles cause occlusion, obscuring the pulse of air from the bicycle that should be counted. Bicycles traveling in groups are similarly difficult to count as shown in the earlier results from the controlled environment special cases tests (bicyclists riding side by side and one behind the other). Some of the equipment tested is better than others at separating out these cases.

Another cause of error is the classification scheme used for the classification counters. For example, when the BOCO scheme was used on the same data for $\mathrm{C} 3$, it increased the accuracy of the bicycle counts. 


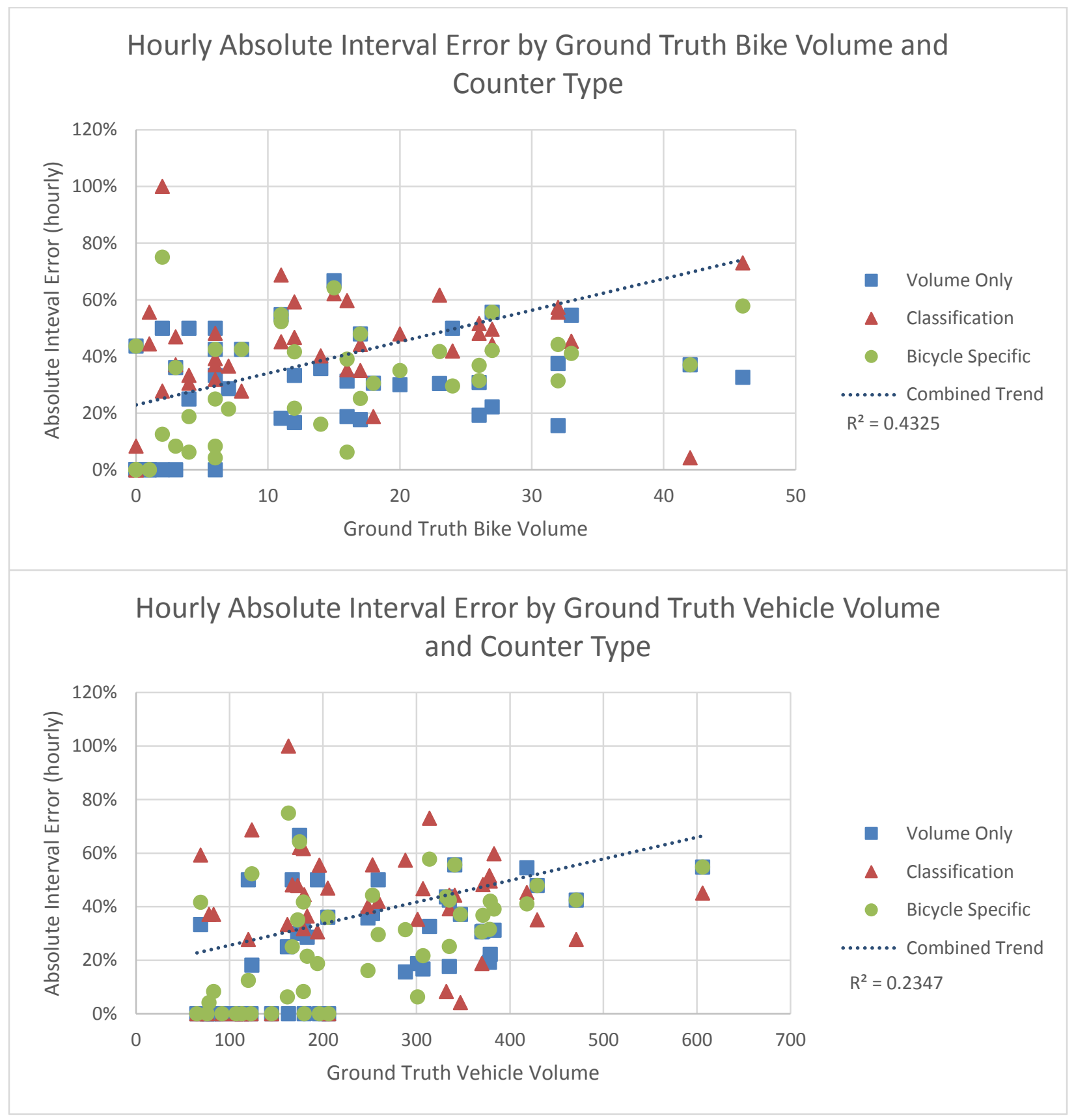

FIGURE 4 Absolute Interval Error with Traffic Volume in Mixed Traffic. 


\section{CONCLUSIONS \& RECOMMENDATIONS}

Using the same pneumatic tubes for counting motor vehicles and bicycles is desirable, but challenging. Weaker air pulses from bicycles can be harder to detect and occlusion can prevent bicycles from being counted. Some bicycles have longer than normal wheelbases or additional wheels, and cyclists like to ride side-by-side or in platoons. Despite these obstacles, jurisdictions would like to be able to count bicycles using the equipment they already have in their inventory an array of motor-vehicle counting equipment.

This study reviews three types of pneumatic tube counting equipment: bicycle-specific, classification, and volume-only counters. The first two are able to distinguish between bicycles and motor vehicles. The second two are commonly available to those who monitor motor-vehicle traffic. Bicycle-specific counters have been found to be accurate in mixed traffic, but do not provide speed or classify motor vehicles. Classification counters offer the opportunity to count bicycles, classify motor vehicles, and provide speed data, but accuracies vary widely. Volume counters should only be used in places where motor vehicles are rare, such as paths or some road shoulders.

Findings from the controlled environment test with no mixed traffic revealed that all of the equipment tested were capable of counting standard bicycles with less than $10 \%$ error within 10 to 15 feet of the count equipment, when no other vehicles are present and only one bicyclist rides over the tubes. The results from the special cases test showed that bicycles riding side-byside, one-behind-the-other, bicycles with trailers, and long wheelbase bicycles are particularly difficult to count using pneumatic tubes.

Findings from the mixed traffic test are listed below.

- Error for all of the equipment tested was high. All equipment in the two-lane highway condition tested undercounted bicyclists, with MPE ranging from $-10 \%(\mathrm{C} 3)$ to $-73 \%$ $(\mathrm{C} 2)$.

- Generally, higher bicycle and motor-vehicle traffic lead to higher undercounts, likely due to occlusion, especially for classification counters.

- Greater error was observed farther from the counting equipment.

- Accuracy can be improved through bicycle-specific changes to classification schemes.

- Bicyclist speed estimates from classification counters, C1 and C3, are consistent with each other and with observed speeds from video.

- A clear relationship between error and bicyclist speed was not observed.

- Some counters were more likely to count false positives (C1, C2 and V1), which can lead to an incorrect understanding of bicycle travel patterns.

False positives, counting motor vehicles as bicycles, should be carefully watched in future studies. Low bicycle traffic on highways mean that even low numbers of vehicles incorrectly identified as bicycles could lead to substantial error and mislead those studying bicycle travel patterns.

When standard motor-vehicle counting equipment is used to count bicycles error can be high but not for all devices. Bicycle-specific counters and some classification counters have lower error. Unexpectedly, in this test, simply using single-tube volume counters in the shoulder had similar error to the bicycle-specific and the two best classification counters. However, this approach should only be used where bicycles travel predictably in the shoulder, motor vehicles 
avoid the shoulder and where bicycle volumes are similar or greater than those observed in this study.

This research contributes to the academic literature on bicycle counting using pneumatic tubes in three ways: 1) it verifies that bicycle speeds given by off-the shelf pneumatic counting equipment are accurate, 2) it shows that in the tested situation, volume-only tubes placed in the shoulder were as accurate as classification counters placed over the entire road, and 3) it reports error in bicycle counting for three types of off-the-shelf pneumatic tube counters and from five manufacturers - more than any previous study.

Regardless of what equipment is used, verification testing should be conducted and care should be taken when setting up the equipment and processing the data. Bicycle counting using pneumatic tubes is a more challenging task than counting motor vehicles and should be approached with attention to detail. 


\section{ACKNOWLEDGEMENTS}

The authors gratefully acknowledge funding support for this study from ODOT. The authors would also like to thank Bill Link, Fraser Groves, Gary Obery, Sheila Lyons, Lyn Cornell, Amanda Owens, Roger Boettcher, Amanda Owings, and Bruce Moody for their participation during the controlled environment testing. Thanks are also due to Don Crownover, Dara Gayler, Will Adams, Phillip Armand, and Rick Hindle and all the vendors for their assistance with equipment set up.

\section{REFERENCES}

1. Federal Highway Administration. Traffic Monitoring Guide. Publication FHWA PL-13015. U.S. Department of Transportation, Washington, D.C., April 2013.

2. Hyde-Wright, A., B. Graham, and K. Nordback. Counting Bicyclists with Pneumatic Tube Counters on Shared Roadways. ITE Journal, February 2014, pp.32-37.

3. Brosnan, M., M. Petesch, J. Pieper, S.Schumacher, G. Lindsey. Validation of Bicycle Counts from Pneumatic Tube Counters in Mixed Traffic Flows. Proceedings of the $94^{\text {th }}$ Annual Meeting of the Transportation Research Board, Transportation Research Board of the National Academies, Washington, D.C., 2015.

4. Griffin, G., K. Nordback, T. Gotschi, E. Stolz, and S. Kothuri. Monitoring Bicyclist and Pedestrian Travel and Behavior. Transportation Research Circular E-C183, Transportation Research Board of the National Academies, Washington D.C., March 2014.

5. Ryus, P., E. Ferguson, K. Laustsen, R. Schenider, F. Proulx, T. Hull, and L. MirandaMoreno. Guidebook on Pedestrian and Bicycle Volume Data Collection. National Cooperative Highway Research Program Report 797, Transportation Research Board of the National Academies, Washington D.C., 2014.

6. Nordback, K., W. Marshall, B. Janson, and Elizabeth Stolz. "Estimating Annual Average Daily Bicyclists: Error and Accuracy." Transportation Research Record, Transportation Research Board of the National Academies, Washington, D.C., 2013.

7. Nosal, Thomas, Luis Miranda-Moreno, and Zlatko Krstulic. "Incorporating Weather: Comparative Analysis of Annual Average Daily Bicyclist Traffic Estimation Methods." Transportation Research Record: Journal of the Transportation Research Board 2468, Transportation Research Board of the National Academies, Washington, D.C., 2014.

8. Hankey, S., G. Lindsey, and Julian Marshall. "Day-of-Year Scaling Factors and Design Considerations for Nonmotorized Traffic Monitoring Programs." Transportation Research Record: Journal of the Transportation Research Board 2468, Transportation Research Board of the National Academies, Washington, D.C., 2014.

9. Hjelkrem, O. A., and T. Giæver. A Comparative Study of Bicycle Detection Methods and Equipment. Presented at the 16th ITS World Congress and Exhibition on Intelligent Transport Systems and Services, Stockholm, Sweden, 2009.

10. ViaStrada Ltd. Continuous Cycle Counting Trial. New Zealand Transport Agency, Auckland, New Zealand, January 2009. Accessed at http://www.nzta.govt.nz/assets/resources/continuous-cycle-countingtrial/docs/continuous-cycle-counting-trial.pdf

11. Ryus, P., F. R. Proulx, R. J. Schneider, T. Hull, and L. Miranda-Moreno. Methods and Technologies for Pedestrian and Bicycle Volume Data Collection. Washington, DC: National Cooperative Highway Research Program, 2015. 